\title{
Autonomic and cardiovascular effects of pentobarbital anesthesia during trigeminal stimulation in cats
}

\author{
Hiroshi Hanamoto, Hitoshi Niwa, Mitsutaka Sugimura and Yoshinari Morimoto
}

Stimulation of the trigeminal nerve can elicit various cardiovascular and autonomic responses; however, the effects of anesthesia with pentobarbital sodium on these responses are unclear. Pentobarbital sodium was infused intravenously at a nominal rate and the lingual nerve was electrically stimulated at each infusion rate. Increases in systolic blood pressure (SBP) and heart rate (HR) were evoked by lingual nerve stimulation at an infusion rate between 5 and $7 \mathrm{mg} \cdot \mathrm{kg}^{-1} \cdot \mathrm{h}^{-1}$. This response was associated with an increase in the low-frequency band of SBP variability (SBP-LF). As the infusion rate increased to $10 \mathrm{mg} \cdot \mathrm{kg}^{-1} \cdot \mathrm{h}^{-1}$ or more, decreases in SBP and $\mathrm{HR}$ were observed. This response was associated with the reduction of SBP-LF. In conclusion, lingual nerve stimulation has both sympathomimetic and sympathoinhibitory effects, depending on the depth of pentobarbital anesthesia. The reaction pattern seems to be closely related to the autonomic balance produced by pentobarbital anesthesia.

International Journal of Oral Science (2012) 4, 24-29; doi:10.1038/ijos.2012.7; published online 2 March 2012

Keywords: autonomic nervous system; blood pressure and heart rate variability; hemodynamics; trigeminal depressor response

\section{INTRODUCTION}

Various cardiovascular and autonomic responses are triggered by noxious stimulation of the oral regions. In urethane-anesthetized rabbits, electrical stimulation of the branches of the trigeminal nerve resulted in reductions of arterial blood pressure (BP) and heart rate (HR). ${ }^{1-3}$ This response was named the trigeminal depressor response (TDR).

Recent studies have indicated that the trigeminally induced cardiovascular reflex could be mediated initially in the trigeminal nucleus caudalis and subsequently in the parabrachial nucleus, A5 cell group (noradrenergic neurons) in the pons, the rostral ventrolateral medulla (RVLM), the dorsal medullary reticular field and the paratrigeminal nucleus. ${ }^{4-7}$ However, the exact pathway initiating TDR remains poorly understood.

TDR does not occur in all animals and species variability exists. ${ }^{8}$ The BP response to trigeminal stimulation was shown to be an increase in rats, and consistent decrease in rabbits and guinea pigs, both anesthetized with urethane. However, in pentobarbital or urethane/ $\alpha$-chloralose-anesthetized cats, electric stimulation of trigeminal nerve caused both pressor and depressor alteration in BP. ${ }^{9-10}$ This variability in BP response in cats reputedly depends mainly on the strength and frequency of stimulus, as well as the anatomical location of the stimulation site. However, bidirectional responses are also produced even using identical stimulus parameters and stimulation site. The mechanism underlying variability in $\mathrm{BP}$ response is not clear.

In most previous studies regarding cardiovascular response to trigeminal stimulation, there was no attention paid to the depth of anesthesia. Pentobarbital, urethane or $\alpha$-chloralose was usually administered intraperitoneally and added when necessary. It would be extremely difficult to maintain a constant depth of anesthesia using such anesthetic methods. Cardiovascular and autonomic functions are significantly affected by the anesthetic agent and depth of anesthesia. Therefore, different responses may be induced by the same stimulation. The present study evaluated the dose effects of pentobarbital anesthesia on cardiovascular and autonomic response to electrical stimulation of the trigeminal nerve in cats.

Because TDR is associated with reduction in total peripheral resistance mainly due to sympathetic inhibition, ${ }^{1}$ it is important to evaluate autonomic function during trigeminal stimulation. Over the past 10 years, numerous attempts have been made to measure the activity of the autonomic nervous system using power spectral analysis of BP and beat-to-beat interval fluctuations. ${ }^{11}$ Recently, power spectral analysis of HR variability and BP variability has been widely used as a noninvasive method for quantifying autonomic function. In the present study, spectral analysis of systolic blood pressure (SBP) and HR is used to assess vascular and cardiac sympathetic and parasympathetic activity. By this method, we can evaluate autonomic function with minimal intervention throughout the study. Data on the $R-R$ interval and SBP were analyzed and two frequency bands were separated into a low-frequency (LF) band $(0.04-0.28 \mathrm{~Hz})$ and a high-frequency (HF) band $(0.28-0.7 \mathrm{~Hz})$. The frequency ranges for defining the LF and HF bands in a cat were based on previous studies. ${ }^{12-15}$ Because the frequency ranges were slightly different among the studies depending on the analysis methods, we took into account the features of wavelet transform and decided the frequency bands.

The LF component of SBP variability (SBP-LF) is increased under conditions associated with various sympathetic activations. ${ }^{16-18}$ Furthermore, SBP-LF is positively correlated with muscular sympathetic 
nerve activity, providing more direct support for the concept of using changes in the SBP-LF as a marker of changes in sympathetic efferent activity in the peripheral vasculature. ${ }^{19}$ Therefore, we consider that SBP-LF can be analyzed to assess sympathetic nervous activity. Power spectral analysis of HR variability is routinely used as a non-invasive means of quantifying cardiac autonomic input. The HF peak represents respiratory sinus arrhythmia and is a reliable indicator of parasympathetic efferent activity. Although plasma catecholamine concentration is a useful index of sympathetic activity, it is not very sensitive to changes in sympathetic nervous activity ${ }^{20-21}$ and repeated samplings of blood to measure catecholamine concentration may influence the autonomic nervous system.

Data analysis was performed with wavelet transformation, because this method has high time-resolving power and enables autonomic modulations to be determined on a per second basis. ${ }^{22-24}$ Wavelet transformation therefore should provide further evidence of the effects of trigeminal stimulation on systemic and cardiac autonomic regulation beyond that obtained from cardiovascular parameters alone. Further details on wavelet transformation have been published elsewhere. $^{25}$

\section{MATERIALS AND METHODS}

The animal protocols were reviewed and approved by the Animal Care and Use Committee, Osaka University Graduate School of Dentistry.

\section{Surgical preparation}

In total, 38 male adult cats (study $1, n=7$; study 2, $n=10$; study 3 , $n=21$ ) weighting $2.8-5.5 \mathrm{~kg}$ were used (Nagoya Lab, Nagoya, Japan). Anesthesia was induced by inhalation of $5 \%$ sevoflurane in oxygen and an endotracheal tube was inserted into the trachea. The right femoral artery and the saphenous vein were cannulated to measure arterial $\mathrm{BP}$ and to administer intravenous drugs and fluids, respectively. After intravenous lactated Ringer's solution was started at $10 \mathrm{~mL} \cdot \mathrm{kg}^{-1} \mathrm{~h}^{-1}$, the animals were paralyzed with $0.5 \mathrm{mg} \cdot \mathrm{kg}^{-1} \cdot \mathrm{h}^{-1}$ vecuronium bromide and mechanically ventilated (SN-480-5; Shinano, Tokyo, Japan) with $30 \%$ oxygen in air. End-tidal $\mathrm{CO}_{2}$ was monitored with a gas monitor (Normocap 200; Datex, Turku, Finland) and was kept in the range of $35-40 \mathrm{mmHg}$. Respiratory frequency was maintained at 30 breaths $\cdot \min ^{-1}$ on the basis of a previous study. ${ }^{26} \mathrm{HR}$ was continuously monitored with an electrocardiograph using needle electrodes. Body temperature was also measured with a rectal probe and maintained at about $38.0{ }^{\circ} \mathrm{C}$ with a heating pad.

\section{Autonomic measurement}

Electrocardiogram and femoral artery pressure waveform were sampled at a rate of $1000 \mathrm{~Hz}$ and stored on a personal computer for later analysis. The first peaks of $R$ waves on the electrocardiograms were detected and then $R-R$ intervals were measured. The peak values of SBP for each cardiac cycle were also obtained. Data on the $R-R$ interval and SBP were analyzed using commercially available software (Fluclet; Dai-nippon Pharmaceutical, Osaka, Japan).

\section{Electrical stimulation of the lingual nerve (LN)}

We stimulated the LN among branches of the trigeminal nerve. The distal LN was dissected free from surrounding connective tissue by an intraoral approach. A bipolar enamel-silver wire electrode $(0.3 \mathrm{~mm}$ in diameter) was placed on the central cut end of the LN. Square wave pulses were delivered using a stimulation unit (SEN-3301; Nihon Kohden, Tokyo, Japan) and isolation unit (SS-202J; Nihon
Kohden). The stimulation condition was $2 \mathrm{~mA}$ in intensity, $10 \mathrm{~Hz}$ in frequency and $5 \mathrm{~ms}$ in duration for $10 \mathrm{~s}$. Stimulus parameters were based on previous studies. $^{9-10}$

\section{Experimental protocol}

Study 1: hemodynamic and autonomic effects of pentobarbital anesthesia. After completion of the experimental preparations, sevoflurane was discontinued and pentobarbital sodium was infused intravenously at a nominal rate of $5,7,10,12$ or $15 \mathrm{mg} \cdot \mathrm{kg}^{-1} \cdot \mathrm{h}^{-1}(n=7)$. Pentobarbital infusion was continued for $75 \mathrm{~min}$ at each administration rate. Twenty minutes after the initial dose of pentobarbital sodium, we confirmed that cats were anesthetized and not awake, because there were no changes in arterial $\mathrm{BP}$ and $\mathrm{HR}$ in response to a fairly minor noxious stimulus such as pinching a lower limb. SBP, HR, HR-HF and SBP-LF were measured 60 min after beginning pentobarbital administration at each rate. A blood sample from the femoral artery was collected at each measurement point to determine plasma pentobarbital concentration using high-performance liquid chromatography.

Study 2: hemodynamic and autonomic effects of electrical stimulation of the LN. Pentobarbital was infused continuously as in study $1(n=10)$. Electrical stimulation of the LN was performed 20 min after beginning pentobarbital administration at each rate. Electrical stimulation was repeated at intervals of $10 \mathrm{~min}$, so data were obtained from six simulations at the same rate of pentobarbital administration. Measurements of SBP, HR, HR-HF and SBP-LF were performed at baseline, 6 and $10 \mathrm{~s}$ after the onset of electrical simulation, and 10,20 and $50 \mathrm{~s}$ after the end of stimulation.

Study 3: hemodynamic and autonomic effects of autonomic blocking agents. When a depressor response of more than $10 \mathrm{mmHg}$ occurred during LN stimulation, atropine $\left(0.25 \mathrm{mg} \cdot \mathrm{kg}^{-1}, n=7\right)$, phentolamine $\left(0.5 \mathrm{mg} \cdot \mathrm{kg}^{-1}, n=7\right)$ or hexamethonium $\left(1.0 \mathrm{mg} \cdot \mathrm{kg}^{-1}, n=7\right)$ was given intravenously, and then the LN was stimulated again to examine the effects of autonomic blocking agents on the depressor response. Hemodynamic and autonomic parameters were measured and compared with those before the administration of each drug.

\section{Statistical analysis}

Data are expressed as the mean \pm SEM. After confirmation of the normal distribution of values by Shapiro-Wilk test, one-way analysis of variance for repeated measurements followed by Dunnett's test for multiple comparisons was used in this study. $P$ values $<0.05$ were considered significant. All statistical analyses were computed using the Statistical Package for Social Sciences (SPSS, Inc., Chicago, IL, USA).

\section{RESULTS}

Hemodynamic and autonomic effects of pentobarbital anesthesia The hemodynamic and autonomic effects of pentobarbital anesthesia are summarized in Table 1 . SBP was significantly decreased at infusion rates of 12 and $15 \mathrm{mg} \cdot \mathrm{kg}^{-1} \cdot \mathrm{h}^{-1}$ compared with that at $5 \mathrm{mg} \cdot \mathrm{kg}^{-1} \cdot \mathrm{h}^{-1}$. HR was also significantly decreased at an infusion rate of $15 \mathrm{mg} \cdot \mathrm{kg}^{-1} \cdot \mathrm{h}^{-1}$. About $80 \%$ suppression of SBP-LF occurred at a $15 \mathrm{mg} \cdot \mathrm{kg}^{-1} \cdot \mathrm{h}^{-1}$ infusion rate compared with that at $5 \mathrm{mg} \cdot \mathrm{kg}^{-1} \cdot \mathrm{h}^{-1}$. HR-HF decreased by about $70 \%$ at 12 and $15 \mathrm{mg} \cdot \mathrm{kg}^{-1} \cdot \mathrm{h}^{-1}$. Plasma pentobarbital concentration increased in a dose-dependent manner and reached $37.2 \mu \mathrm{g} \cdot \mathrm{mL}^{-1}$ at the maximal infusion rate. 
Table 1 Effects of pentobarbital anesthesia on cardiovascular and autonomic parameters (values are the mean \pm SEM of seven cats)

\begin{tabular}{|c|c|c|c|c|c|}
\hline \multirow[b]{2}{*}{ Parameters } & \multicolumn{5}{|c|}{ Pentobarbiturate infusion rate $/\left(\mathrm{mg} \cdot \mathrm{kg}^{-1} \cdot \mathrm{h}^{-1}\right)$} \\
\hline & 5 & 7 & 10 & 12 & 15 \\
\hline $\mathrm{SBP} / \mathrm{mmHg}$ & $207.2 \pm 13.3$ & $192.6 \pm 11.0$ & $189.3 \pm 8.8$ & $165.1 \pm 8.6 *$ & $146.4 \pm 8.9 *$ \\
\hline $\mathrm{SBP}-\mathrm{LF} /\left(\mathrm{mmHg} \cdot \mathrm{Hz}^{-1 / 2}\right)$ & $0.14 \pm 0.04$ & $0.09 \pm 0.02$ & $0.07 \pm 0.03$ & $0.06 \pm 0.02$ & $0.03 \pm 0.02 *$ \\
\hline $\mathrm{HR}-\mathrm{HF} /\left(\mathrm{ms} \cdot \mathrm{Hz}^{-1 / 2}\right)$ & $1.19 \pm 0.38$ & $0.92 \pm 0.39$ & $0.47 \pm 0.15$ & $0.34 \pm 0.08 *$ & $0.31 \pm 0.05^{*}$ \\
\hline $\begin{array}{l}\text { Plasma pentobarbiturate } \\
\text { concentration } /\left(\mathrm{mg}^{-1} \mathrm{~mL}^{-1}\right)\end{array}$ & $6.8 \pm 0.3$ & $12.7 \pm 0.8^{*}$ & $20.6 \pm 1.0 *$ & $27.6 \pm 1.3^{*}$ & $37.2 \pm 1.6^{*}$ \\
\hline
\end{tabular}

Abbreviations: HR, heart rate; HR-HF, high-frequency power of heart rate; SBP, systolic blood pressure; SBP-LF, low-frequency power of systolic blood pressure. $* P<0.05$ versus $5 \mathrm{mg} \cdot \mathrm{kg}^{-1} \cdot \mathrm{h}^{-1}$.

\section{Hemodynamic and autonomic effects of LN stimulation}

Figure 1 shows the maximal changes of SBP in response to electrical stimulation of the LN. In 10 cats, data were obtained from a total of 328 stimulations. Pressor response was evoked by LN stimulation at an infusion rate between 5 and $7 \mathrm{mg} \cdot \mathrm{kg}^{-1} \cdot \mathrm{h}^{-1}$ pentobarbital, while depressor response was evoked at $10 \mathrm{mg} \cdot \mathrm{kg}^{-1} \cdot \mathrm{h}^{-1}$ or more. With an increase in the dose of pentobarbital, the pressor response converted to a depressor response; however, at the maximal rate of pentobarbital, the depressor response was likely to be reduced again. Depressor response was reduced within $10 \mathrm{mmHg}$ at $20 \mathrm{mg} \cdot \mathrm{kg}^{-1} \cdot \mathrm{h}^{-1}$. As shown in Figure 1, blood pressure responses differed even at the same infusion rate as the infusion time increased.

On the basis of the SBP findings, the BP response to LN stimulation was classified into the following four phases:

- phase 1: pressor response of $10 \mathrm{mmHg}$ or more $(n=97)$;

- phase 2: SBP changes within $\pm 10 \mathrm{mmHg}$ following phase 1 $(n=75)$;

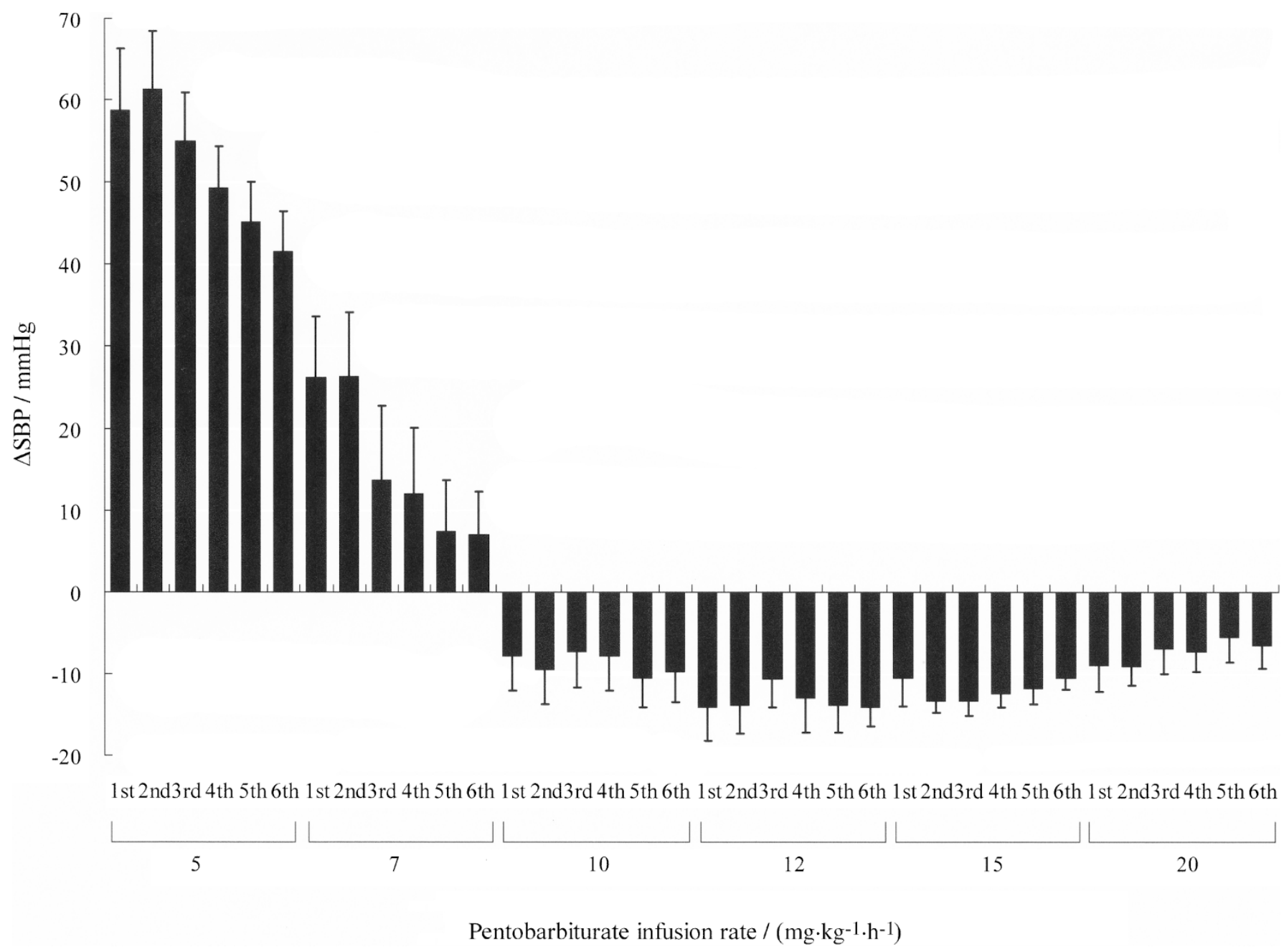

Figure 1 Effects of pentobarbital anesthesia on changes in systolic blood pressure due to LN stimulation. The LN was stimulated six times at each rate of pentobarbital sodium administration. In the 10 cats, there was an overall total of 328 stimulations. Values are the mean \pm SEM of 10 cats. 
Table 2 Effects of LN stimulation on cardiovascular and autonomic parameters (values are the mean \pm SEM of 10 cats; data obtained in each phase were averaged in each cat)

\begin{tabular}{|c|c|c|c|c|c|c|c|}
\hline \multirow[b]{2}{*}{ Phase } & \multirow[b]{2}{*}{ Parameters } & \multirow[b]{2}{*}{ Baseline } & \multicolumn{2}{|c|}{ During stimulation } & \multicolumn{3}{|c|}{ After stimulation } \\
\hline & & & $6 s$ & $10 \mathrm{~s}$ & $10 \mathrm{~s}$ & $20 \mathrm{~s}$ & $50 \mathrm{~s}$ \\
\hline \multirow[t]{4}{*}{1} & $\mathrm{SBP} / \mathrm{mmHg}$ & $176.6 \pm 7.8$ & $203.3 \pm 10.2^{*}$ & $218.1 \pm 9.0 *$ & $189.9 \pm 6.9$ & $176.5 \pm 5.9$ & $173.0 \pm 7.0$ \\
\hline & $\mathrm{HR} /\left(\right.$ beats $\left.\cdot \mathrm{min}^{-1}\right)$ & $193.8 \pm 11.6$ & $211.2 \pm 10.5$ & $211.5 \pm 10.7$ & $171.5 \pm 7.6 *$ & $181.4 \pm 9.7$ & $189.1 \pm 11.1$ \\
\hline & $\mathrm{SBP}-\mathrm{LF} /\left(\mathrm{mmHg} \cdot \mathrm{Hz}^{-1 / 2}\right)$ & $0.10 \pm 0.02$ & $0.22 \pm 0.12$ & $0.41 \pm 0.10^{*}$ & $0.05 \pm 0.03$ & $0.07 \pm 0.03$ & $0.04 \pm 0.02$ \\
\hline & $\mathrm{HR}-\mathrm{HF} /\left(\mathrm{ms} \cdot \mathrm{Hz}^{-1 / 2}\right)$ & $1.80 \pm 0.67$ & $0.40 \pm 0.10$ & $0.47 \pm 0.17$ & $3.11 \pm 0.72$ & $2.79 \pm 0.76$ & $2.39 \pm 0.76$ \\
\hline \multirow[t]{4}{*}{2} & $\mathrm{SBP} / \mathrm{mmHg}$ & $168.5 \pm 7.4$ & $167.8 \pm 8.7$ & $168.3 \pm 8.7$ & $164.8 \pm 8.1$ & $167.2 \pm 7.6$ & $167.8 \pm 7.9$ \\
\hline & $\mathrm{HR} /\left(\right.$ beats $\left.\cdot \mathrm{min}^{-1}\right)$ & $195.2 \pm 10.2$ & $193.5 \pm 10.3$ & $199.6 \pm 10.7$ & $194.6 \pm 9.9$ & $194.6 \pm 9.8$ & $197.3 \pm 10.1$ \\
\hline & $\mathrm{SBP}-\mathrm{LF} /\left(\mathrm{mmHg} \cdot \mathrm{Hz}^{-1 / 2}\right)$ & $0.09 \pm 0.04$ & $0.06 \pm 0.04$ & $0.04 \pm 0.01$ & $0.07 \pm 0.06$ & $0.12 \pm 0.08$ & $0.05 \pm 0.03$ \\
\hline & $\mathrm{HR}-\mathrm{HF} /\left(\mathrm{ms} \cdot \mathrm{Hz}^{-1 / 2}\right)$ & $0.59 \pm 0.21$ & $0.39 \pm 0.13$ & $0.29 \pm 0.07$ & $0.46 \pm 0.21$ & $0.67 \pm 0.14$ & $0.51 \pm 0.13$ \\
\hline \multirow[t]{4}{*}{3} & $\mathrm{SBP} / \mathrm{mmHg}$ & $166.5 \pm 8.5$ & $155.6 \pm 8.4^{*}$ & $149.1 \pm 7.8^{*}$ & $162.5 \pm 8.2$ & $160.4 \pm 8.2$ & $162.9 \pm 9.2$ \\
\hline & $\mathrm{HR} /\left(\right.$ beats $\left.\cdot \mathrm{min}^{-1}\right)$ & $200.9 \pm 8.4$ & $191.3 \pm 7.6^{*}$ & $195.7 \pm 7.6^{*}$ & $204.9 \pm 8.8$ & $200.7 \pm 8.8^{*}$ & $201.1 \pm 8.8$ \\
\hline & $\mathrm{SBP}-\mathrm{LF} /\left(\mathrm{mmHg} \cdot \mathrm{Hz}^{-1 / 2}\right)$ & $0.09 \pm 0.02$ & $0.03 \pm 0.02 *$ & $0.01 \pm 0.01 *$ & $0.05 \pm 0.02$ & $0.02 \pm 0.01 *$ & $0.05 \pm 0.02$ \\
\hline & $\mathrm{HR}-\mathrm{HF} /\left(\mathrm{ms} \cdot \mathrm{Hz}^{-1 / 2}\right)$ & $0.49 \pm 0.07$ & $0.54 \pm 0.13$ & $0.45 \pm 0.09$ & $0.62 \pm 0.17$ & $0.45 \pm 0.08$ & $0.54 \pm 0.11$ \\
\hline \multirow[t]{4}{*}{4} & $\mathrm{SBP} / \mathrm{mmHg}$ & $120.4 \pm 7.6$ & $117.7 \pm 7.6^{*}$ & $116.0 \pm 7.5^{*}$ & $117.2 \pm 7.1^{*}$ & $119.6 \pm 7.0$ & $122.1 \pm 8.0$ \\
\hline & $\mathrm{HR} /\left(\right.$ beats $\left.\cdot \mathrm{min}^{-1}\right)$ & $151.1 \pm 5.7$ & $147.1 \pm 5.6$ & $148.7 \pm 5.4$ & $152.0 \pm 5.6$ & $152.3 \pm 5.6$ & $150.7 \pm 5.6$ \\
\hline & $\mathrm{SBP}-\mathrm{LF} /\left(\mathrm{mmHg} \cdot \mathrm{Hz}^{-1 / 2}\right)$ & $0.01 \pm 0.01$ & $0.01 \pm 0.01$ & $0.00 \pm 0.00$ & $0.00 \pm 0.00$ & $0.00 \pm 0.00$ & $0.01 \pm 0.01$ \\
\hline & $\mathrm{HR}-\mathrm{HF} /\left(\mathrm{ms} \cdot \mathrm{Hz}^{-1 / 2}\right)$ & $0.61 \pm 0.12$ & $0.67 \pm 0.22$ & $0.63 \pm 0.15$ & $0.65 \pm 0.17$ & $0.58 \pm 0.12$ & $0.68 \pm 0.15$ \\
\hline
\end{tabular}

Abbreviations: HR, heart rate; HR-HF, high-frequency power of heart rate; SBP, systolic blood pressure; SBP-LF, low-frequency power of systolic blood pressure. $* P<0.05$ versus baseline value.

Table 3 Effects of autonomic blocking agents on changes in cardiovascular and autonomic parameters after LN stimulation (values are the mean \pm SEM of seven cats for each autonomic blocking agent)

\begin{tabular}{|c|c|c|c|c|c|c|}
\hline \multirow[b]{2}{*}{ Parameters } & \multicolumn{2}{|c|}{ Atropine } & \multicolumn{2}{|c|}{ Hexamethonium } & \multicolumn{2}{|c|}{ Phentolamine } \\
\hline & $(-)$ & $(+)$ & $(-)$ & $(+)$ & $(-)$ & $(+)$ \\
\hline $\mathrm{SBP} / \mathrm{mmHg}$ & $-11.3 \pm 2.5$ & $-9.0 \pm 1.9$ & $-13.5 \pm 2.8$ & $-4.4 \pm 1.4 *$ & $-11.3 \pm 0.9$ & $-4.2 \pm 1.7 *$ \\
\hline $\mathrm{HR} /\left(\right.$ beats$\left.\cdot \mathrm{min}^{-1}\right)$ & $-6.2 \pm 2.5$ & $-3.0 \pm 1.8$ & $-3.4 \pm 1.1$ & $-1.7 \pm 0.3$ & $-2.3 \pm 1.1$ & $-2.3 \pm 1.2$ \\
\hline $\mathrm{SBP}-\mathrm{LF} /\left(\mathrm{mmHg} \cdot \mathrm{Hz}^{-1 / 2}\right)$ & $-0.07 \pm 0.04$ & $-0.02 \pm 0.02$ & $-0.03 \pm 0.01$ & $0.00 \pm 0.00 *$ & $-0.04 \pm 0.00$ & $0.00 \pm 0.00$ \\
\hline $\mathrm{HR}-\mathrm{HF} /\left(\mathrm{ms} \cdot \mathrm{Hz}^{-1 / 2}\right)$ & $-0.14 \pm 0.15$ & $-0.03 \pm 0.10$ & $-0.12 \pm 0.15$ & $-0.06 \pm 0.03$ & $-0.12 \pm 0.15$ & $-0.02 \pm 0.02$ \\
\hline
\end{tabular}

Abbreviations: HR, heart rate; HR-HF, high-frequency power of heart rate; SBP, systolic blood pressure; SBP-LF, low-frequency power of systolic blood pressure.

$* P<0.05$ for comparison of autonomic blocking agents $(+)$ and $(-)$.

- phase 3: depressor response of $10 \mathrm{mmHg}$ or more $(n=113)$;

- phase 4: depressor response within $10 \mathrm{mmHg}$ following phase 3 $(n=43)$.

SBP, HR, HR-HF and SBP-LF in each phase were analyzed during and after LN stimulation (Table 2).

In phase $1, \mathrm{SBP}$ increased from $176.6 \pm 7.8 \mathrm{mmHg}$ up to $218 \pm 9.0 \mathrm{mmHg}$ at the end of stimulation. HR increased during stimulation; however, this increase was not significant. HR decreased transiently $10 \mathrm{~s}$ after stimulation. SBP-LF increased from $0.10 \pm$ $0.02 \mathrm{mmHg} \cdot \mathrm{Hz}^{-1 / 2}$ to $0.41 \pm 0.10 \mathrm{mmHg} \cdot \mathrm{Hz}^{-1 / 2}$ during stimulation and returned to the baseline value after stimulation. HR-HF was reduced during stimulation and increased after stimulation; however, these responses were not significantly different.

In phase 2, there were no significant changes in any parameters.

In phase 3 , SBP decreased from $166.5 \pm 8.5 \mathrm{mmHg}$ to $149.1 \pm$ $7.8 \mathrm{mmHg}$ at the end of stimulation. HR also decreased from $200.9 \pm 8.4$ beats $\cdot \mathrm{min}^{-1}$ to $191.3 \pm 7.6$ beats $\cdot \mathrm{min}^{-1}$ during stimulation. Although there were no significant changes in HR-HF, SBP-LF was reduced from $0.09 \pm 0.02 \mathrm{mmHg} \cdot \mathrm{Hz}^{-1 / 2}$ to $0.03 \pm$ $0.02 \mathrm{mmHg} \cdot \mathrm{Hz}^{-1 / 2}$ during stimulation.
In phase 4, SBP decreased slightly during and after stimulation; however, the other parameters did not change upon LN stimulation.

Hemodynamic and autonomic effects of autonomic blocking agents on TDR (Table 3)

Atropine did not affect the depressor response due to LN stimulation; however, phentolamine and hexamethonium blunted the depressor response. The reduction in SBP-LF produced by LN stimulation was abolished by phentolamine and hexamethonium.

\section{DISCUSSION}

Many studies have shown that trigeminal stimulation produced various responses of arterial BP and HR in animal models; however, anesthetic levels were not always closely controlled. ${ }^{8,10}$ The hemodynamic response to nociceptive stimulation may be influenced by the potentially different plane of anesthesia that animals experience at the various sampling times. ${ }^{27} \mathrm{We}$ evaluated the cardiovascular and autonomic responses to LN stimulation at specific plasma pentobarbital concentrations.

We chose pentobarbital sodium as an anesthetic agent, because it is widely used for producing anesthesia in animal research into 
autonomic control of the cardiovascular system, including Dellow and Morgan's study, ${ }^{9}$ and the cardiovascular and autonomic effects of this agent are well known. ${ }^{28-31}$ Pentobarbital was infused intravenously at a specific rate for strict control of the depth of anesthesia and plasma pentobarbital concentration was measured at each infusion rate. The LN was stimulated to evoke hemodynamic and autonomic response, because previous studies showed that LN stimulation often produced both pressor and depressor response in cats. ${ }^{9-10}$

In the present study, it was observed that, during light anesthesia with pentobarbital, LN stimulation activated the sympathetic nervous system and led to increases in BP and HR, while under moderate anesthesia, BP and HR fell due to LN stimulation and TDR developed. The blockade of sympathetic nervous activity contributed to the reductions in $\mathrm{BP}$ and $\mathrm{HR}$. The $\mathrm{BP}$ response to $\mathrm{LN}$ stimulation depends strongly on the depth of pentobarbital anesthesia.

It was impossible to achieve a stable basal state to ensure interpretable results under an awake condition in a cat, because the animal was alert to everything in the environment. Although it is desirable to achieve a stable basal state using an anesthetic agent, the stability in itself is insufficient to produce useful data, because of the possibility that the autonomic response of the animal to a stimulus may be substantially modified. Therefore, we did not measure any parameters in an awake state.

Light pentobarbital anesthesia (plasma pentobarbital concentration $<25 \mu \mathrm{g} \cdot \mathrm{mL}^{-1}$ ) was associated with significantly higher catecholamine concentrations and catecholamine concentration was maximally suppressed when pentobarbital concentrations were in the range of $25-30 \mu \mathrm{g} \cdot \mathrm{mL}^{-1}$ in dogs. ${ }^{32}$ After the induction of pentobarbital, the concentration of plasma norepinephrine tended to decrease initially and then increase during the later period. This increase in plasma norepinephrine seemed to correlate with the change in RSNA. ${ }^{28-29}$ These previous findings suggest the acceleration of sympathetic nervous activity under light pentobarbital anesthesia. Under such autonomic conditions, trigeminal stimulation caused significant increases in SBP and HR. This response was associated with an increase in SBPLF, which suggests acceleration of sympathetic nervous activity. After LN stimulation, suppression of SBP-LF and acceleration of HR-HF were observed, as well as a rapid drop in HR; however, these changes were not significant. These autonomic responses may reflect the arterial baroreceptor reflex.

When plasma pentobarbital concentration was greater than 25$30 \mu \mathrm{g} \cdot \mathrm{mL}^{-1}$, the increase in plasma catecholamine concentration was fully suppressed. ${ }^{32}$ In the present study, a similar anesthetic level was achieved when pentobarbital was administered at a rate of $12 \mathrm{mg} \cdot \mathrm{kg}^{-1} \cdot \mathrm{h}^{-1}$. At this anesthetic level, HR-HF was reduced significantly compared with that under light anesthesia. Although SBP-LF was suppressed slightly, this change was not significant. Therefore, autonomic balance was considered to remain predominantly sympathetic; however, each autonomic condition was quite different from that under light anesthesia. Under such a specific autonomic condition, trigeminal stimulation caused suppression of sympathetic nervous activity, leading to the reductions in SBP and HR, and TDR developed.

A sympathetic predominant state was necessary in order to develop TDR; ${ }^{33}$ however, TDR never developed under mere enhancement of sympathetic activity under light anesthesia. The addition of halothane inhalation was required to elicit TDR under light urethane anesthesia in rabbits, ${ }^{34}$ which suggests a specific autonomic condition for TDR.
When the anesthetic level became more profound (15$20 \mathrm{mg} \cdot \mathrm{kg}^{-1} \cdot \mathrm{h}^{-1}$ ), SBP-LF was also reduced greatly as well as HR-HF. At this anesthetic level, LN stimulation did not affect either SBP-LF or HR-HF and the cardiovascular response was greatly reduced.

Previous investigators used pharmacological methods to confirm that TDR was induced by the suppression of sympathetic nervous activity. ${ }^{1-2,8,35}$ In the present study, we demonstrated that SBP-LF was reduced during TDR and that TDR was blunted by phentolamine and hexamethonium. To our knowledge, this is the first report to describe the autonomic effects of TDR using spectral analysis of BP and $\mathrm{HR}$ variability.

We demonstrated that electric LN stimulation induces a sympathomimetic or sympathoinhibitory effect at different anesthestic levels. TDR could be mediated by RVLM, a tonic descending vasomotoractivating center. ${ }^{36}$ GABA could mediate the inhibitory transmission from the caudal ventrolateral medulla to the RVLM. ${ }^{33}$ Anesthetic level might alter the GABAergic activity to RVLM and control pressor or depressor response induced by electrical stimulation. However, the reason why anesthetic level alters the sympathomimetic or sympathoinhibitory effect induced by electrical stimulation is still controversial.

In clinical situations, painful stimulation of the orofacial region during dental treatment frequently causes increases in HR and BP. ${ }^{37}$ However, painful stimulation to the oral region has been considered a trigger for the development of syncope or fainting as a stress-induced vasovagal reaction. ${ }^{38}$ Many researchers and clinicians have speculated that TDR is a major trigger for this reaction. Syncope or fainting is more likely to occur in anxious patients, whose sympathetic nervous activity is usually enhanced due to fear and anxiety about dental procedures. ${ }^{39}$ However, the present study showed that trigeminal stimulation did not produce TDR under light anesthesia where sympathetic nervous activity was predominant. Although our study is not a human study but an animal study, and pentobarbital is not used in clinical human patients, TDR might not be a trigger of the depressor response such as syncope or fainting in clinical situations. Painful stimulation may be a major factor reinforcing fear and anxiety. The fact that fainting or syncope often develops without painful stimulation may support this view. As TDR develops only under specific autonomic balance, TDR might not be of any importance in the clinical setting.

Trigemino-cardiac reflex (TCR) is a brainstem reflex that is defined as the sudden onset of parasympathetic dysrhythmia, sympathetic hypotension, apnea, or a gastric hypermotility during stimulation of any sensory branches of the trigeminal nerve, commonly induced by ophthalmic division of the trigeminal nerve and sometimes occurs during skull base surgery. ${ }^{40-41}$ Recently, TCR has been recognized to be the same as TDR. ${ }^{42-43}$ If the mechanisms of TCR and TDR are the same, the occurrence of TCR might be associated with anesthetic levels. Further investigations are needed to clarify the unknown mechanisms of TCR and TDR.

\section{CONCLUSION}

Trigeminal stimulation produced various blood pressure responses depending on the depth of pentobarbital anesthesia. During light pentobarbital anesthesia, LN stimulation has sympathomimetic effects, while it has sympathoinhibitory effects during moderate anesthesia, leading to TDR. TDR develops when the autonomic condition shifts toward sympathetic predominance without enhancement of sympathetic nervous activity itself. TDR develops only at a certain depth of anesthesia in cats. 


\section{ACKNOWLEDGEMENTS}

This work was financially supported by our department (Department of Dental Anesthesiology, Osaka University Graduate School of Dentistry).

1 Kumada M, Dampney RA, Reis DJ. The trigeminal depressor response: a cardiovascular reflex originating from the trigeminal system. Brain Res 1975 92(3): 485-489.

2 Kumada M, Dampney RA, Reis DJ. The trigeminal depressor response: a nove vasodepressor response originating from the trigeminal system. Brain Res 1977 119(2): 305-326.

3 Kumada M, Dampney RA, Whitnall MH et al. Hemodynamic similarities between the trigeminal and aortic vasodepressor responses. Am J Physiol 1978; 234(1): H67H73.

4 Allen GV, Barbrick B, Esser MJ. Trigeminal-parabrachial connections: possible pathway for nociception-induced cardiovascular reflex responses. Brain Res 1996; 715(1/2): 125-135.

5 Allen GV, Pronych SP. Trigeminal autonomic pathways involved in nociceptioninduced reflex cardiovascular responses. Brain Res 1997; 754(1/2): 269-278.

6 Esser MJ, Pronych SP, Allen GV. Trigeminal-reticular connections: possible pathways for nociception-induced cardiovascular reflex responses in the rat. J Comp Neurol 1998; 391(4): 526-544.

7 de Sousa Buck H, Caous CA, Lindsey CJ. Projections of the paratrigeminal nucleus to the ambiguus, rostroventrolateral and lateral reticular nuclei, and the solitary tract. Auton Neurosci 2001; 87(2/3): 187-200.

8 Koeda S, Yasuda M, Izumi H. Species differences in the reflex effects of lingual afferent nerve stimulation on lip blood flow and arterial pressure. J Comp Physiol B 2003; 173(8): 629-636.

9 Dellow PG, Morgan MJ. Trigeminal nerve inputs and central blood pressure change in the cat. Arch Oral Biol 1969; 14(3): 295-300.

10 Izumi H, Mizuta K, Kuchiiwa S. Simultaneous measurement of parasympathetic reflex vasodilator and arterial blood pressure responses in the cat. Brain Res 2002; 952(1): 61-70.

11 Akselrod S, Gordon D, Ubel FA et al. Power spectrum analysis of heart rate fluctuation: a quantitative probe of beat-to-beat cardiovascular control. Science $1981 ; 13(4504)$ : 220-222.

12 Montano N, Lombardi F, Gnecchi Ruscone T et al. Spectral analysis of sympathetic discharge, R-R interval and systolic arterial pressure in decerebrate cats. J Auton Ner Syst 1992; 40(1): 21-31.

13 Nagai $\mathrm{H}$, Suzuki T, Katsumata $\mathrm{N}$ et al. Effect of non-depolarizing muscle relaxants on autonomic nervous system activity - assessment by heart rate variability analysis. Masui 1999; 48(12): 294-301.

14 Rey S, Del Rio R, Alcayaga J et al. Chronic intermittent hypoxia enhances cat chemosensory and ventilatory responses to hypoxia. J Physiol 2004; 560(Pt 2): 577-586.

15 Abbott JA. Heart rate and heart rate variability of healthy cats in home and hospital environments. J Feline Med Surg 2005; 7(3): 195-202.

16 Cooke WH, Hoag JB, Crossman AA et al. Human responses to upright tilt: a window on central autonomic integration. J Physiol 1999; 517(Pt 2): 617-628.

17 Weise F, Laude D, Girard A et al. Effects of the cold pressor test on short-term fluctuations of finger arterial blood pressure and heart rate in normal subjects. Clin Auton Res 1993; 3(5): 303-310.

18 Pagani M, Furlan R, Pizzinelli $\mathrm{P}$ et al. Spectral analysis of $R-R$ and arterial pressure variabilities to assess sympatho-vagal interaction during mental stress in humans. $J$ Hypertens 1989; 7(6): S14-S15.

19 Pagani M, Montano N, Porta A et al. Relationship between spectral components of cardiovascular variabilities and direct measures of muscle sympathetic nerve activity in humans. Circulation 1997; 95(6): 1441-1448.

20 Hjemdahl P. Physiological aspects on catecholamine sampling. Life Sci 1987; 41(7) $841-844$.
21 Hjemdahl P. Plasma catecholamines - analytical challenges and physiological limitations. Baillieres Clin Endocrinol Metab 1993; 7(2): 307-353.

22 Pichot V, Gaspoz JM, Molliex S et al. Wavelet transform to quantify heart rate variability and to assess its instantaneous changes. J Appl Physiol 1999; 86(3): 1081-1091.

23 Suzuki M, Hori S, Nakamura I et al. Role of vagal control in vasovagal syncope. Pacing Clin Electrophysiol 2003; 26(2 Pt 1): 571-578.

24 Belova NY, Mihaylov SV, Piryova BG. Wavelet transform: a better approach for the evaluation of instantaneous changes in heart rate variability. Auton Neurosci 2007; 131(1/2): 107-122.

25 Ivanov PC, Rosenblum MG, Peng CK et al Scaling behaviour of heartbeat intervals obtained by wavelet-based time-series analysis. Nature 1996; 383(6598): 323-327.

26 Crosfill ML, Winddicombe JG. Physical characteristics of the chest and lungs and the work of breathing in different mammalian species. J Physiol 1961; 158(1): 1-14.

27 Samso E, Farber NE, Kampine JP et al. The effects of halothane on pressor and depressor responses elicited via the somatosympathetic reflex: a potential antinociceptive action. Anesth Analg 1994; 79(5): 971-979.

28 Matsukawa K, Ninomiya I. Anesthetic effects on tonic and reflex renal sympathetic nerve activity in awake cats. Am J Physiol 1989; 256(2 Pt 2): R371-R378.

29 Matsukawa K, Ninomiya I, Nishiura N. Effects of anesthesia on cardiac and rena sympathetic nerve activities and plasma catecholamines. Am J Physiol 1993; 265(4 Pt 2): R792-R797.

30 Shimokawa A, Kunitake T, Takasaki M et al. Differential effects of anesthetics on sympathetic nerve activity and arterial baroreceptor reflex in chronically instrumented rats. J Auton Nerv Syst 1998; 72(1): 46-54.

31 Cheng Y, Cohen B, Oréa V et al. Baroreflex control of renal sympathetic nerve activity and spontaneous rhythms at Mayer wave's frequency in rats. Auton Neurosci 2004 111(2): 80-88.

32 Baum D, Halter JB, Taborsky GJ Jr et al. Pentobarbital effects on plasma catecholamines: temperature, heart rate, and blood pressure. Am J Physiol 1985; 248(1 Pt 1): E95-E100.

33 Ohshita N, Nakajo N, Takemura M. Characteristics of the trigeminal depressor response in cats. J Neurosci Res 2004; 76(6): 891-901.

$34 \mathrm{Yu}$ YH, Blessing WW. Constriction of the ear pinna vascular bed accompanies the trigeminal depressor response in rabbits. Neurosci Lett 1998; 255(3): 172-174.

35 Yasuda M, Izumi H. Trigeminal nerve-mediated reflex arterial blood pressure decrease and vasodilatation in lower lip of the rabbit. Brain Res 2003; 987(1): 59-66.

36 Terui N, Saeki Y, Kumada M. Barosensory neurons in the ventrolateral medulla in rabbits and their responses to various afferent inputs from peripheral and central sources. Jpn J Physiol 1986; 36(6): 1141-1164.

37 Gortzak RA, Abraham-Inpijn L. Pain-induced hypertensive episode in the denta office. Gen Dent 1995; 43(3): 274-276.

38 Ichinohe $\mathrm{T}$, Agata $\mathrm{H}$, Aida $\mathrm{H}$ et al. Cerebral cortex regional blood flow and tissue oxygen tension during the trigeminal depressor response in rabbits. J Auton Nerv Syst 1997 66(1/2): 111-118

39 Edmondson HD, Roscoe B, Vickers MD. Biochemical evidence of anxiety in denta patients. Br Med J 1972; 4(5831): 7-9.

40 Schaller B. Trigeminocardiac reflex. A clinical phenomenon or a new physiological entity? J Neurol 2004; 251(6): 658-665.

41 Schaller B, Cornelius JF, Prabhakar $\mathrm{H}$ et al. The trigemino-cardiac reflex: an update of the current knowledge. J Neurosurg Anesthesiol, 2009; 21(3): 187-195.

42 Meng Q, Yang Y, Zhou M et al. Trigemino-cardiac reflex: the trigeminal depressor responses during skull base surgery. Clin Neurol Neurosurg 2008; 110(7): 662-666.

43 Schaller B, Sandu N, Filis A et al. Trigemino-cardiac reflex: the trigeminal depresso responses during skull base surgery. Clin Neurol Neurosurg, 2009; 111(2): 220.

This work is licensed under a Creative Commons Attribution-NonCommercial-NoDerivative Works 3.0 Unported License. To view a copy of this license, visit http:// creativecommons.org/licenses/by-nc-nd/3.0 